\title{
An Overview of Dominant Research Approaches to Measure Intercultural Communication Competence (ICC)
}

\author{
Muhammad Umar Nadeem ${ }^{1}$, Rosli Mohammed ${ }^{2}$, Syarizan Dalib ${ }^{3}$
}

\begin{tabular}{l} 
ARTICLE INFO \\
\hline Article History: \\
Received 15.06.2018 \\
Received in revised form \\
27.08.2018 \\
Accepted \\
Available online 01.10 .2018
\end{tabular}

\section{INTRODUCTION}

Over the years, it has been noticed that several theoretical approaches developed so far which enable the intercultural researchers to facilitate the literature of intercultural competence with a sound contribution. There are six vital research approaches to engage ICC: Anxiety/uncertainty management (AUM) theory (Gudykunst, 2005), Personal network approach (Kim, 1986), Systems theory approach (Kim, 1995, 2002), Social skills perspective (Martin \& Hammer 1989), Identity negotiation perspective and Knowledge of host culture and attitude towards the other culture (Wiseman, Hammer \& Nishida, 1989). The following paragraphs addresses various dominant research approaches to measure intercultural communication competence (ICC).

\section{DOMINANT RESEARCH APPROACHES}

The most promising attempt has been done by Gudykunst (1995) in the form of Anxiety Uncertainty Management Theory (AUM), in which he introduced a causal relationship among anxiety and uncertainty management are the basic causes of effective communication among the strangers. A further contribution to the theory is that, the identification of several "superficial causes" that influences the effectiveness of communication and leads to intercultural adjustment (Gudykunst, 2005) of the strangers. These variables are considered as the elements of ICC because intercultural adaptation reflects ICC. Nevertheless, it has not been the priority of the researcher to notice the behavior of the in dividual who is having aw areness but unable to reduce the uncertainty and anxiety (Gudykunst, 1998).

Gudykunst effort has not given the weight to one of the conceivable influencers of ICC which is, individuals' personal network that leads to the communication competence of the people of other cultures. Kim (1986) introduced Personal netw ork approach and investigated that variable in her research and further suggested for the upcoming researches of ICC, to incorporate network approach. It is also argued that intercultural competence is always influenced by the individuals' personal network. Furthermore, when an individual is having a heterogeneous personal network, then the individual is expected to be more competent in intercultural interactions. Nevertheless, no attempts have been done to address these mentioned propositions.

${ }^{1}$ Corresponding e-mail: umarnadeemx@gmail.com,orcid.org/0000-0001-6613-6355, Universiti Utara Malaysia ${ }^{1}$, Universiti Utara Malaysia ${ }^{2}$, Universiti Utara Malaysia $^{3}$ 
Another effort by Kim (1995) in the form of Systems theory approach is grounded on the open systems prepositions regarding the nature of individuals relating to the flexible beings. ICC and cultural competence have been eminent by Kim (2002) because if anyone is competent in a specific culture that does not necessarily means that person should be competent in an intercultural context. That is why, she associated ICC with the inside ability of the individual (Kim, 1995). Intercultural adaptability has been distinguished by Kim as the ability of the person to change its existing structures and characteristics to fulfill the requirements of the given condition (Kim, 1991) and adaptability is the vital element of ICC. Additionally, individual's adaptability is reflected from the skills of the individual to be flexible in an unknown culture during the intercultural communication. Regarding the adaptability, she identified three elements of ICC: behavioral, cognitive and affective.

Social skills perspective has been acknowledged by Martin and Hammer (1989). On the other side, perceived communication competence has been witnessed by several researchers. Martin and Hammer (1989) argue that "this view of competence as the social impression is useful because it can be equally applied to the study of within culture competence (an intracultural context) and betw een culture competence (an intercultural context)" (p. 305). While a continuity of the research practice has been started about the pros and cons of self-reported and presentation grounded data for getting the evidence. It is empirically demonstrated that individuals are skillful about shimmering their communication practices to deliver the stance which is utilized in the self-reports (Riggio \& Riggio, 2001). In the previous researches, a key problem administered is that most of the times the research subjects are having very less intercultural experience and they were supposed to provide information about their prior intercultural interactions in the self-reports.

Wiseman, Hammer, and Nishida (1989) introduced a different perspective on the conceptualization of ICC and they refer to it as the multidimensional construct. To name a few essential factors that contribute well to ICC are the attitude tow ards other cultures and the knowledge of the host culture. It is apparently assumed that their conceptualization of ICC seems to be quite similar to Kim (1991) cultural competence approach. The relationship among the knowledge of host culture and ICC has been addressed by the Japanese and American students. Though, the findings of their research could not consider under the umbrella of ICC because their focused research subjects were two cultures and research linked with cultural competence as identified by Kim (2002). As well as, Collier (1989) mentioned that if the research is investigated among the individuals of multiple cultural backgrounds then the theory will be considered as the culture-general theory.

Another approach to study ICC is the cultural identity approach. To conceptualize ICC, Ting-Toomey (1993) introduced an Identity Negotiation Process Model which comprises behavioral, affective and cognitive elements that mediate among effective identity negotiation and multiple-self-identification process. She defines ICC as "the effective negotiation process between two interactants in a novel communication episode" (p. 73). The most repeated elements of intercultural competence research are behavioral, affective and cognitive. Furthermore, a variable like empathy, cognitive complexity, and several other social skills are pointed out by the researches of interpersonal communication competence (Spitzberg \& Cupach, 1984).

These abovementioned approaches exposed that these researches have follow ed the perspective of one culture which further indicates the existence of cultural biases in these approaches of intercultural competence (Arasaratnam, 2007). In other words, one can assume that these approaches as the culturespecific approach to measure ICC. For example, Yoshitake (2002) argued the presence of western biases (America) in the AUM theory and while extending this theory to different cultures necessarily contains the values of America in intercultural communication. A study by Wiseman et al. (1989) focused on the two cultural perspectives (Japan and America) and have also encountered the almost similar issue of biasedness. Arasaratnam (2007) mentioned that the intentions of the intercultural researchers are according to the inclination of their own culture and affected by their societal filters. Furthermore, she suggested that the researcher should make sure that the model of ICC is free from the biasedness of any culture. 


\section{CULTURE GENERAL APPROACH}

The most logical technique to eliminate the factor of biasedness of any specific culture from the models of ICC is that, to integrate multiple cultural perspectives in developing the model. Collier (1989) have mentioned the criteria of culture general approach is that to incorporate multiple cultural perspectives in the study. Various researches have employed particular methodological procedures to adopt culture general approach.

Dillon and McKenzie (1998) have explored the impact of ethnicity on the respondents' self-reported observation of communication competence in the presence of various variables. By the survey technique, data were gathered. The outcome of the research has witnessed that there were ethnic variations regarding the observation of intercultural competence of the respondents. The researchers further suggested for the upcoming communication competence researchers those are adopting a culture-general approach to unpack the issue of cultural dissimilarities.

A study conducted by Driskill and Downs (1995) in an organizational environment on the Euro American and the migrants of Asian Indian. The aim of the study was to explore the differentiation of understanding in the intercultural rules and to discover the nature of competence. Findings of the study revealed that the rules regarding intercultural interaction enable the individuals to interact with the people of dominant culture.

Knutson, Komolsevin, Chatiketu, and Smith (2003) explored the rhetorical sensitivity among the students of USA and Thailand through the survey. The respondents were selected from the Bangkok and California. The researchers found that the students of Thailand were on the lower levels of rhetorical sensitivity as compared to Americans. It was concluded that a virtuous self-behavior could deter ICC. At this end, it is evident that the prerequisite of culture general approach is to incorporate the multiple cultural perspectives and it can be generalized universally to the other cultures (Arasaratnam, 2007; Collier, 1989).

Arasaratnam claimed that culture general approach is such an approach which focus on the similarities between the respondents who belongs to the multiple cultural perspectives (p. 8, 2016). For instance, if an individual is competent in specific cultural context, does not necessarily be competent in another. Earlier in this section, the discussed approaches have been influenced by some social filters and cultural bonding. How ever, it is plausible to look for intersections of ICC elements betw een multiple cultural perspectives.

Arasaratnam and Doerfel (2005) study offered a significant w ork w orthy to be considered for a research that utilizes culture-general approach. The grounded reasons behind this approach were that to be aw are of the similarities among the respondents who belong to the multiple cultures in determining ICC and lack of evidence in the previous researchers whether these researches could be generalized to multiple cultures or not. Respondents were questioned by the researchers to define ICC according to their own observation. In that research, 15 countries have got the representation in the form of 37 respondents and the dominant themes about this explanation were analyzed through semantic network analysis. After analysis, five variables appeared, namely motivation, experience in intercultural communication, ability to listen, empathy with the individuals that belong to of different cultures and positive attitude tow ards the people from other cultures. Despite any specific cultural perspective, these variables influence the intercultural competence (Arasaratnam, 2016). This research is considered as the beginning of the culture-general model of ICC, for the identification of such contributors that influence ICC. The outcomes were encouraging but, there is a lacking concerning its testing extensively.

Later, Arasaratnam (2006) have developed a culture-general model of ICC by relying on the initial efforts of Arasaratnam and Doerfel (2005). The identified variables have been addressed empirically in the new culture general model of ICC (Arasaratnam, 2006). Next section represents a comprehensive overview of various culture general models of Arasaratnam which have been developed so far.

\section{ARASARATNAM'S CULTURE-GENERAL MODELS OF ICC}

Previously, five key influencers of intercultural competence have been identified by the study of Arasaratnam and Doerfel (2005). These variables are Empathy, Motivation, Global Attitude, Experience and 
Interaction Involvement that leads to ICC. One of the most notew orthy characteristics of these variables is that these variables are culture general variables (Arasaratnam, 2016) which mean they are not having any specific cultural perspective and contributes to intercultural competence. Arasaratnam (2006) developed a new culture general model of intercultural competence by incorporating these variables to empirically address the direct and indirect relationship of the variables that influence intercultural competence of the individual.

Data was collected by adopting the technique of survey and the further analysis was done by incorporating the regression analysis in AMOS. Respondents of the study were the university students (Caucasian Americans). The results of the study showed that ICC was having a positive significant relationship with the motivation, interaction involvement, and empathy. Interaction involvement was having a positive significant relationship with attitudes towards other cultures and empathy but, insignificant relationship with motivation. Furthermore, attitude towards other cultures was having a positive significant relationship with motivation, experience, and empathy. Motivation was having a positive significant relationship with the experience. Lastly, empathy and experience were not having any significant correlation between them. The results were promising, and it was recommended by the researcher to apply this model and test it on the culturally diverse participants.

This model has been developed because of the strong recommendations made by early efforts in concerning the variables that influence intercultural friendship (Morgan \& Arasaratnam, 2003). These studies found that intercultural contact seeking behavior is influenced by the personality feature which is, sensation seeking. Nevertheless, these mentioned researches have not provided a portion of ethnocentrism in their models. Besides that, it is an established path that ethnocentrism is one of the variables which is unfavorably connected with the intercultural interaction (Lin \& Rancer, 2003; Neuliep, Chaudoir, \& McCroskey, 2001; Neuliep \& McCroskey, 1997). Therefore, Arasaratnam has adopted ethnocentrism as the independent variable in the model of intercultural friendship.

A different culture general model as compared to the previous model (Arasaratnam, 2006) of ICC developed by Arasaratnam and Banerjee (2007) to find out sensation seeking and ethnocentrism as the forecaster of intercultural contact pursuing behavior. Data was collected from the university students through the survey technique and further analyzed through the multiple regression analysis. The researchers found that intercultural friendship was having a positive significant relationship with motivation and negative relationship with ethnocentrism. Sensation seeking was having a positive significant relationship with motivation and social initiative. There was a positive significant relationship among motivation and social initiative. Ethnocentrism was having a negative relationship with social initiative and motivation besides that, a negative correlation with sensation seeking.

The findings of the study exposed that ethnocentrism hinders the sensation seekers to formulate the intercultural friendship and reduces the motivation of the individual to make a relation with the people of multiple cultural backgrounds. Finally, the researcher concluded that the presence of ethnocentrism could not be ignored, and it is the factor which adversely influences the relationship of other variables that leads to intercultural friendship or interaction. Therefore, this model has given the better understanding about the predictors of intercultural contact seeking behavior.

The Integrated Model of Intercultural Communication Competence (IMICC) has appeared to be the most remarkable contribution to the history of intercultural competence by Arasaratnam Banerjee and Dembek. This model is one of the among rare culture general models of ICC that have been empirically addressed till now. It is developed grounding on the perception of individuals about ICC from multiple cultural perspectives (Arasaratnam, Banerjee, \& Dembek, 2010a) to reduce the biasedness of culture.

A study by Arasaratnam and Doerfel (2005) has been considered as the benchmark in the development of culture general model of ICC. Arasaratnam (2006) model has been incorporated as the base model to propose an IMICC model in order to address the weaknesses of the previous model. The previous model has focused on the students of America (Arasaratnam, 2006). But, for the IMICC the researchers a ddressed the model among the students of Australia, to change the context and to examine the convenience of IMICC among multiple cultures. SEM technique has been adopted for the very first time in IMICC and the data analyzed through AMOS (Arasaratnam et al., 2010a). 
Variables remained the same as indicated in the prior researches (Arasaratnam, 2006; Arasaratnam \& Doerfel, 2005). Experience and empathy were treated as the independent variables. Motivation, interaction involvement and attitude tow ards other cultures treated as the mediating variables and finally, ICC as the dependent variable. Three new paths were added in the model to meet the statistical assumptions. The findings of the study were inclined toward the results of the prior studies. However, few new theoretical contributions were also noticed.

A new pathway showed that empathy is indirectly influenced by interaction involvement and motivation and then leads to ICC. Secondly, motivation indirectly affects the relationship between empathy and ICC besides that, empathy directly contributes to ICC as well. Thirdly, empathy is indirectly influenced by the attitude tow ards other culture and approach to ICC but, the findings showed that attitude tow ards other cultures does have a direct relationship with ICC. Lastly, the findings have not supported the relationship of attitudes tow ards other cultures and experience.

For this reason, the researcher justified that IMICC is addressed in the different context as compared to the previous model test (Arasaratnam, 2006) and most importantly, the research respondents are also from the different cultural backgrounds. This factor affects the variations in the findings due to changing the context. Overall, the findings of IMICC have given deep insight into the theoretical contributions. Researchers further recommended to further retest and refine this model and address it among multiple cultures.

Another research conducted by Arasaratnam, Banerjee, and Dembek (2010b) to explore the relationship of sensation seeking besides other variables that usually leads to intercultural communication competence within the framew ork of Integrated Model of Intercultural Communication Competence (Arasaratnam et al., 2010a). It is apparently the extension of previous culture general model of ICC which is, IMICC. For this model, the basic determination was to incorporate sensation seeking in the model. Sensation seeking is seen as the contributing factor to ICC by past researchers (Arasaratnam \& Banerjee, 2007; Morgan \& Arasaratnam, 2003). Another reason was that to address sensation seeking with the other associated variables that lead to ICC, to examine their relationship and retest the previous findings of the culture-general model of ICC.

The data was collected from the students of the Australian university in the form of survey and analyzed by using AMOS. The researchers replace the variable experience form the IMICC model (Arasaratnam et al., 2010a) with the sensation-seeking (Arasaratnam et al., 2010b). The findings of the research revealed that sensation seeking is having a positive significant relationship with empathy, interaction involvement and attitude tow ards other cultures. Though, the relationship of sensation seeking remains insignificant with ICC. Researchers concluded that the relationship of sensation seeking with ICC only exists in the presence of various mediating variables. At this end, it was recommended that this stripe of investigation is still in its initial phases and needs further purification and retesting of culture general model is required among other cultures.

The most recent culture general model has been developed by Arasaratnam and Banerjee in 2011. There were several objectives behind the development of this model. Firstly, Arasaratnam and Banerjee (2011) intended to retest the previous culture general model of intercultural competence and for the determination of relationship among sensation seeking and ICC. Secondly, the model tests mediating variables that may influence the relationship between sensation seeking and ICC. Lastly, the model tests ethnocentrism in the presence of other positive influencers to ICC.

According to the results of the previous line of researches about ICC (Arasaratnam, 2006; Arasaratnam \& Banerjee, 2007; Arasaratnam et al., 2010a, 2010b). A new model was tested by Arasaratnam and Banerjee (2011), which was focused on the relationship of sensation seeking in the attendance of mediating variables, that is the attitude towards other culture (ATOC) and motivation with ICC. The resear chers altered the framew ork of the previous model (Arasaratnam \& Banerjee, 2007) by replacing two variables with the new variables. Intercultural friendship was changed by ICC and the social initiative was changed by ATOC. The respondents were the students of an Australian university. Respondent's data was gathered by survey method and structural equation modeling was performed. The participants of above-mentioned culturegeneral models were the students of specific institutions, which were identical to the studies of other 
disciplines who considered the student population to meet the objectives of their researches (Kapikiran \& Gundogan, 2018; Saputri, Rukayah, \& Indriayu, 2018).

The findings of the research have witnessed that sensation seeking was having a positive indirect relationship with ICC in the presence of mediating variables like motivation and ATOC (Nadeem, Mohammed, \& Dalib, 2018). In addition, ethnocentrism w as having a negative relationship with motivation, sensation seeking, ATOC, and ICC. Therefore, ethnocentrism was found to be adversely related with other variables and even in the presence of ethnocentrism in the model, the relationship of other variables was also affected in contributing to ICC.

\section{CONCLUSION}

Over the last couple of years, research in intercultural competence has been more focused on the culture-general approach regarding the conception of ICC (Witteborn, 2003). This approach has been effectively articulated by the Lilly Arasaratnam in her different above discussed empirical culture general models of ICC (Arasaratnam, 2006; Arasaratnam \& Banerjee, 2007, 2011; Arasaratnam et al., 2010a, 2010b). While we acknowledge the effort and remarkable contributions of Arasaratnam to the field of intercultural competence in developing the various culture general models of ICC.

As already been discussed in detail about the specific cultural approach in the previous section, it is evident that a couple of western researchers have incorporated the culture-specific approach and assume it to be "universally generalize among multiple cultures" (Arasaratnam, 2007; Collier, 1989; Gudykunst, 1993; Wiseman et al., 1989). However, it is also witnessed that, if an individual is competent in one specific cultural context, might not be competent in other cultural another (Arasaratnam, 2016). That is why Arasaratnam and Doerfel (2005) argues that there is a lack of evidence on whether previous researches can be generalized to multiple cultures or not. Thus, she looked for similarities of ICC features among culturally diverse participants in her study. Despite the fact that these culture general models are still addressed in the western context (Arasaratnam, 2006; Arasaratnam \& Banerjee, 2007, 2011; Arasaratnam et al., 2010a, 2010b). Cultural context does have a strong impact on the conceptualization of intercultural competence (Dalib, Harun, \& Yusof, 2014, 2017; Nadeem, Mohammed, \& Dalib, 2017b; Yeh, 2010; Yum, 2012).

However, various researchers have pointed out to re-test the culture-general models of ICC among different cultural contexts (Arasaratnam, 2006, 2007, 2016; Arasaratnam et al., 2010a, 2010b). It is an upsurge need to consider these recommendations from the previous researchers and it is plausible to look for intersections of ICC elements between different cultural perspectives. For these reasons, the upcoming researches should incorporate the framework of the most recent culture general model of ICC by Arasaratnam and Banerjee (2011). Another culture general model proposed by Nadeem, Mohammed, and Dalib (2017a) regarding the Non-Western context of Malaysia might be useful for the future researchers to reconfirm the culture-general nature of variables as well as the model. To sum up, this paper has discussed in detail about the dominant research approaches to measure ICC and their weaknesses in generalizing the findings to other cultures. Thus, this study is limited to the literature only because it has not addressed these discussed gaps from an empirical standpoint. Therefore, it is suggested that the upcoming researchers have the wider area to investigate the systematic influence of various predictors influencing intercultural communication competence (ICC) based on the culture-general approach. These sorts of studies can definitely generalize their findings on the multiple cultures and extend the understanding of the complex nature of intercultural communication competence (ICC).

\section{REFERENCES}

Arasaratnam, L. A. (2006). Further testing of a new model of intercultural communication competence. Communication Research Reports, 23(2), 93-99.

Arasaratnam, L. A. (2007). Research in intercultural communication competence: Past perspectives and future directions. Journal of International Communication, 13(2), 66-73. 
Arasaratnam, L. A. (2016, February). Intercultural competence. Oxford Research Encyclopedia of Communication (pp. 01-23). USA: Oxford University Press.

Arasaratnam, L. A., \& Banerjee, S. C. (2007). Ethnocentrism and sensation seeking as variables that influence intercultural contact-seeking behavior: A path analysis. Communication Research Reports, 24(4), 303310.

Arasaratnam, L. A., \& Banerjee, S. C. (2011). Sensation seeking and intercultural communication competence: A model test. International Journal of Intercultural Relations, 35(2), 226-233.

Arasaratnam, L. A., Banerjee, S. C., \& Dembek, K. (2010a). The integrated model of intercultural communication competence (IMICC): Model test. Australian Journal of Communication, 37(3), 103-116.

Arasaratnam, L. A., Banerjee, S. C., \& Dembek, K. (2010b). Sensation seeking and the integrated model of intercultural communication competence. Journal of Intercultural Communication Research, 39(2), 69-79.

Arasaratnam, L. A., \& Doerfel, M. L. (2005). Intercultural communication competence: Identifying key components from multicultural perspectives. International Journal of Intercultural Relations, 29(2), 137163.

Collier, M. J. (1989). Cultural and intercultural communication competence: Current approaches and directions for future research. International Journal of Intercultural Relations, 13(3), 287-302.

Dalib, S., Harun, M., \& Yusof, N. (2017). Student intercultural competence in a Malaysian campus: A phenomenological approach. Journal of Multicultural Discourses, 12(1), 42-62.

Dalib, S., Harun, M., \& Yusoff, N. (2014). Reconceptualizing intercultural competence: A phenomenological investigation of students' intercultural experiences. Procedia-Social and Behavioral Sciences, 155, 130135.

Dillon, R. K., \& McKenzie, N. J. (1998). The influence of ethnicity on listening, communication competence, approach, and avoidance. International Journal of Listening, 12(1), 106-121.

Driskill, G. W., \& Downs, C. W. (1995). Hidden differences in competent communication: A case study of an organization with Euro-Americans and first generation immigrants from India. International Journal of Intercultural Relations, 19(4), 505-522.

Gudykunst, W. B. (1993). Tow ard a theory of effective interpersonal and intergroup com munication: An anxiety/uncertainty management (AUM) perspective. In R. L. Wiseman \& J. Koester (Eds.), Intercultural communication competence (Vol. 17, pp. 33-71). Thousand Oaks, CA, US: Sage Publications, Inc.

Gudykunst, W. B. (1995). Anxiety/uncertainty management (AUM) theory: Current status. In R. L. Wiseman (Eds.), Intercultural communication theory (Vol. 19, pp. 8-58). Thousand Oaks, CA, US: Sage Publications, Inc.

Gudykunst, W. B. (1998). Applying anxiety \uncertainty management (AUM) theory to intercultural adjustment training. International Journal of Intercultural Relations, $22(2), 227-250$.

Gudykunst, W. B. (2005). An anxiety/uncertainty management (AUM) theory of strangers' intercultural adjustment. In W. B. Gudykunst (Eds.), Theorizing about intercultural communication (pp. 419-457). Thousand Oaks, CA: SAGE.

Kapikiran, N. A., \& Gundogan, A. (2018). Assessment for children's values: Picture-Based value survey for children adaptation study. International Journal of Educational Research Review, 3(2), 9-21. 
Kim, Y. Y. (1986). Understanding the social context of intergroup communication: A personal network approach. In W. B. Gudykunst (Eds.), Intergroup communication (pp. 86-95). London: Edward Arnold.

Kim, Y. Y. (1991). Intercultural communication competence: A systems theoretic view. In S. Ting-Toomey, \& F. Korzenny (Eds.), Cross-cultural interpersonal communication (pp. 259-275). Newbury Park,CA: Sage.

Kim, Y. Y. (1995). Cross-cultural adaptation: An integrative theory. In R. L. Wiseman (Eds.), Intercultural communication theory (pp. 170-193). Thousand Oaks, CA: Sage.

Kim, Y. Y. (2002). Adapting to an unfamiliar culture. In W. B. Gudykunst \& B. Mody (Eds.), Handbook of international and intercultural communication (pp. 259-273). Thousand Oaks, CA: Sage.

Knutson, T. J., Komolsevin, R., Chatiketu, P., \& Smith, V. R. (2003). A cross-cultural comparison of Thai and US American rhetorical sensitivity: Implications for intercultural communication effectiveness. International Journal of Intercultural Relations, 27(1), 63-78.

Lin, Y., \& Rancer, A. S. (2003). Ethnocentrism, intercultural communication apprehension, intercultural willingness-to-communicate, and intentions to participate in an intercultural dialogue program: Testing a proposed model. Communication Research Reports, 20(1), 62-72.

Martin, J. N., \& Hammer, M. R. (1989). Behavioral categories of intercultural communication competence: Everyday communicators' perceptions. International Journal of Intercultural Relations, 13(3), 303-332.

Morgan, S., \& Arasaratnam, L. (2003). Intercultural friendships as social excitation: Sensation seeking as a predictor of intercultural friendship seeking behavior. Journal of Intercultural Communication Research, $32(3 / 4), 175-186$.

Nadeem, M. U., Mohammed, R., \& Dalib, S. (2017a). A proposed model of intercultural communication competence (ICC) in Malaysian context. International Journal of Educational Research Review, 2(2), 1120.

Nadeem, M. U., Mohammed, R., \& Dalib, S. (2017b). Religion and intercultural communication competence. Journal of Philosophy, Culture and Religion, 28(3), 25-29.

Nadeem, M. U., Mohammed, R., \& Dalib, S. (2018, March). Historical development and models of intercultural communication competence (ICC). Paper presented at the SMMTC Postgraduate Symposium 2018, University Utara Malaysia, Malaysia.

Neuliep, J. W., Chaudoir, M., \& McCroskey, J. C. (2001). A cross-cultural comparison of ethnocentrism among Japanese and United States college students. Communication Research Reports, 18(2), 137-146.

Neuliep, J. W., \& McCroskey, J. C. (1997). The development of a US and generalized ethnocentrism scale. Communication Research Reports, 14(4), 385-398.

Riggio, R. E., \& Riggio, H. R. (2001). Self-report measurement of interpersonal sensitivity. In J. A. Hall, \& F. J. Bernieri (Eds.), Interpersonal sensitivity: Theory and measurement (pp. 124-142). Mahwah, NJ: Erlbaum.

Saputri, D. Y., Rukayah, R., \& Indriayu, M. (2018). Need assessment of interactive multimedia based on game in elementary school: A challenge into learning in 21st century. International Journal of Educational Research Review, 3(3), 1-8.

Spitzberg, B. H., \& Cupach, W. R. (1984). Interpersonal communication competence. Beverly Hills, CA: Sage. 
Ting-Toomey, S. (1993). Communicative resourcefulness: An identity negotiation perspective. In R. L. Wiseman \& J. Koester (Eds.), Intercultural communication competence (Vol. 17, pp. 72-111). Thousand Oaks, CA, US: Sage Publications, Inc.

Wiseman, R. L., Hammer, M. R., \& Nishida, H. (1989). Predictors of intercultural communication competence. International Journal of Intercultural Relations, 13(3), 349-370.

Witteborn, S. (2003). Communicative competence revisited: An emic approach to studying intercultural communicative competence. Journal of Intercultural Communication Research, 32(3), 187-203.

Yeh, J. B. (2010). Relations matter: redefining communication competence from a Chinese perspective. Chinese Journal of Communication, 3(1), 64-75.

Yoshitake, M. (2002). Anxiety/uncertainty management (AUM) theory: A critical examination of an intercultural communication theory. Intercultural Communication Studies, 11(2), 177-193.

Yum, J. O. (2012). Communication competence: A Korean perspective. China Media Research, 8(2), 11-18. 